\title{
A RARE CASE OF BILATERAL VARIANT ANSA CERVICALIS AND REVIEW OF LITERATURE
}

\section{Suma $H Y^{1}$, Yogesh A S ${ }^{1}$, Shanthini $S^{2}$.}

${ }^{1}$ Jawaharlal Institute of Postgraduate Medical Education and Research, Puducherry, India.

${ }^{2}$ Sri Lakshmi Narayana Institute of Medical Sciences, Puducherry, India.

\section{ABSTRACT}

Ansa cervicalis is a nerve loop that is embedded in the anterior wall of carotid sheath of the neck. It is formed by descendent hypoglossi and descendens cervicalis. It supplies the infrahyoid muscles. During routine dissection, a rare variant in the morphology of Ansa cervicalis was observed in adult male cadaver. The variant ansa cervicalis exhibited two loops, and was present bilaterally. The formation, course and relations of the nerve loop is complex. During literature search, we came across studies which propose different classifications. Hence we have added a note on the different classifications.

Ansa cervicalis is important since it can be used in nerve-nerve anastomosis, nerve-muscle pedicle implantation in relation to reconstructive surgeries of larynx. Hence, the knowledge of variations in the formation, and distribution is relevant. It can affect the outcome during reinnervation surgeries following recurrent laryngeal paralysis and surgeries around this area of neck.

KEY WORDS: Ansa Cervicalis, Cervical Plexus, Reinnervation Of Larynx, Infrahyoid Muscles, Recurrent Laryngeal Nerve Paralysis.

Address for Correspondence: Dr. Suma H Y, Additional Professor, Department of Anatomy, Jawaharlal Institute of Postgraduate Medical Education and Research, Puducherry, India Phone-9442550603; E-Mail: suma1478@gmail.com

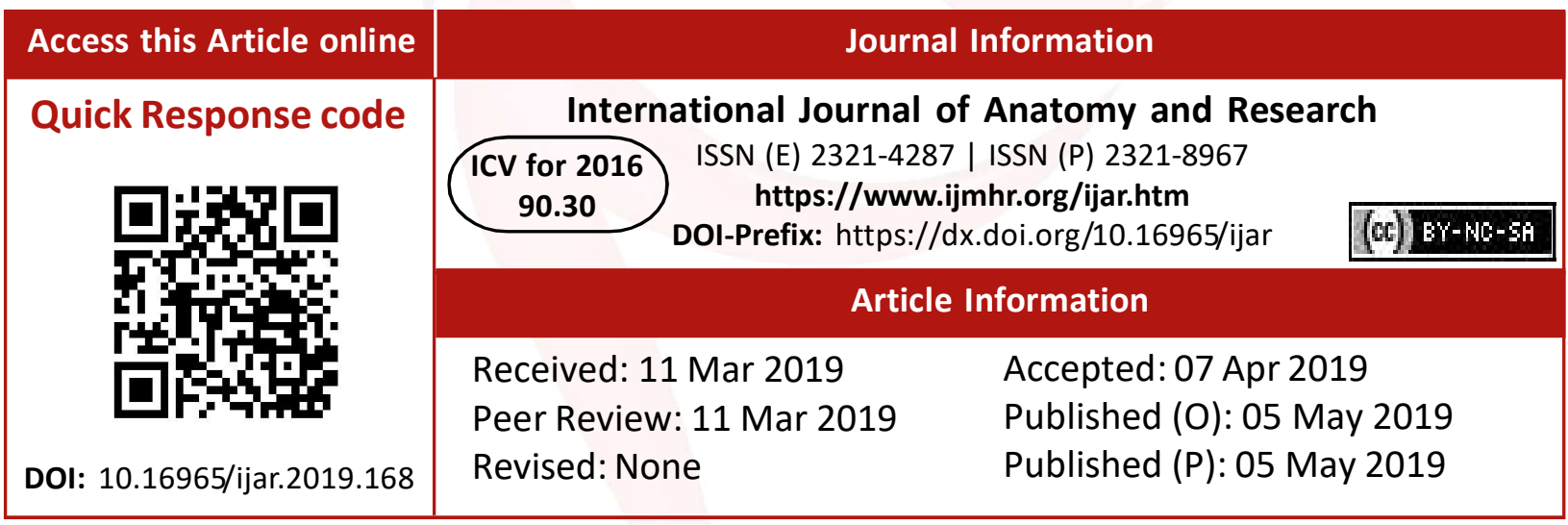

\section{INTRODUCTION}

Ansa cervicalis is a nerve loop that is embedded in the anterior wall of carotid sheath in the anterior triangle of neck. The term Ansa is derived from Latin word "Ansa" meaning handle of a cup. It innervates the infrahyoid strap muscles of neck [1].

Ansa cervicalis $(A C)$ is formed by the ventral rami of first three cervical spinal nerves (C1-3). It is formed by a) Superior root (also called descendens hypoglossi) that contains $\mathrm{C} 1$ fibersgiven off by Hypoglossal nerve and the $b$ ) Inferior root (also called descendens cervicalis) carrying C2 and C3 fibers, from the cervical plexus. Relations in the neck- the superior root descends in front of internal and common carotid artery. The inferior root passes down in relation to the internal jugular vein. The nerve loop innervates the infrahyoid muscles which move larynx, hence important in speech production [2].

Its clinical utility in reinnervation of paralyzed laryngeal muscles has been described in literature. It can be nerve-muscle implantation or nerve-nerve anastomosis. The nerve-muscle anastomosis following accidental recurrent laryngeal nerve paralysis has been described. Ansa cervicalis is preferred for such procedures 
due to close proximity to larynx, and doesn't result in significant disability or cosmetic outcome. Ansa cervicalis is also being used for indirect facial nerve reconstruction and facialhypoglossal anastomosis [3].

During the course of routine dissection, we observed variation in the formation of ansa cervicalis not described in literature. The present case is being reported and, it will add to the possible variants of ansa cervicalis.

Authors have tried to classify the types of ansa cervicalis using different yard sticks. We attempt to highlight the different classifications based on formation and relations of ansa cervicalis.

\section{Case report findings:}

During routine dissection in an adult male cadaver, the ansa cervicalis showed variations in its formation.

\section{Right AC (Fig 1)-}

The inferior root of ansa cervicalis (IRAC) from cervical plexus contributing to $A C$ was by two loops. The superior loop of AC carrying fibers of $\mathrm{C} 2$, traversed down behind the posterior belly of digastric muscle, further between the right common carotid artery (CCA) and right internal jugular vein (IJV). Then it joined with descendens hypoglossi in front of right CCA, the superior loop was $2 \mathrm{~cm}$ above the intermediate tendon of omohyoid.

The inferior loop contributed by $\mathrm{C} 3$, given off posterior to right IJV, then it descended between IJV and right CCA. The inferior loop was just superior to intermediate tendon of omohyoid, and joined with the SRAC.

\section{Left AC (Fig 2):}

The left $A C$ side also consisted of two loops. The superior loop from C2 was given at the level of posterior belly of digastric, which coursed between left CCA and the left IJV. It anastomosed with the superior root of AC (SRAC) at an acute angle at the level of cricoid cartilage, instead of the usual U-shaped loop observed in traditional anatomy. The root from $\mathrm{C} 3$ along with $\mathrm{C4}$, join as single nerve trunk and form the inferior loop of $A C$ behind the left internal jugular vein. It joined with $A C$ below the superior belly of omohyoid (SBO).

The SRAC from Hypoglossal nerve carrying C1 fibers had normal course on both the sides of neck.

Fig. 1: Formation of the double looped ansa cervicalis on the right side.

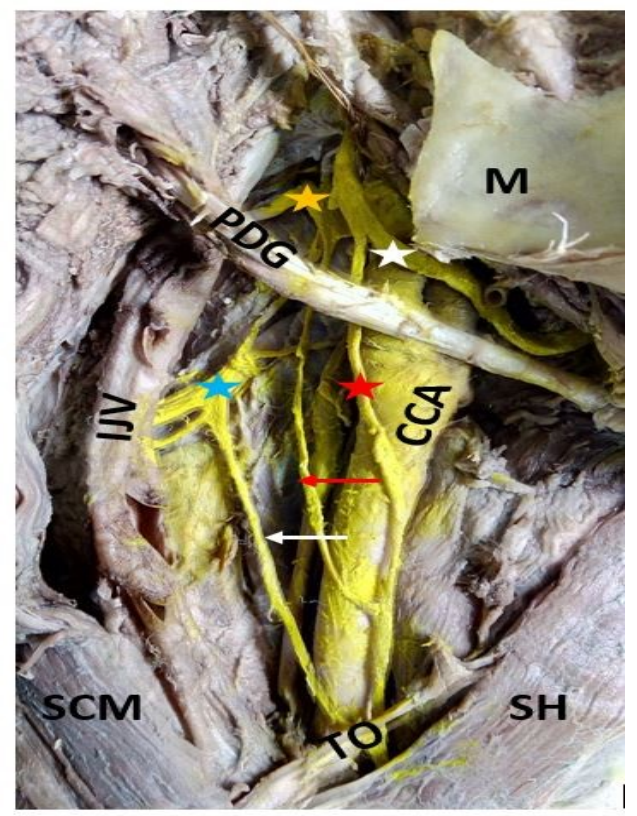

CCA - common carotid artery, IJV - Internal Jugular Vein, M - Mandible, PDG - Posterior belly of Digastric, SCM - Sternocleidomastoid, SH - Sternohyoid, TO - Intermediate tendon of Omohyoid, White star - Hypoglossal Nerve, Red star - Descendant Hypoglossi, Orange star - C2, Blue star - C3, Red Arrow - First Loop, White Arrow - Second Loop

Fig. 2: Formation of the double looped ansa cervicalis on the left side.

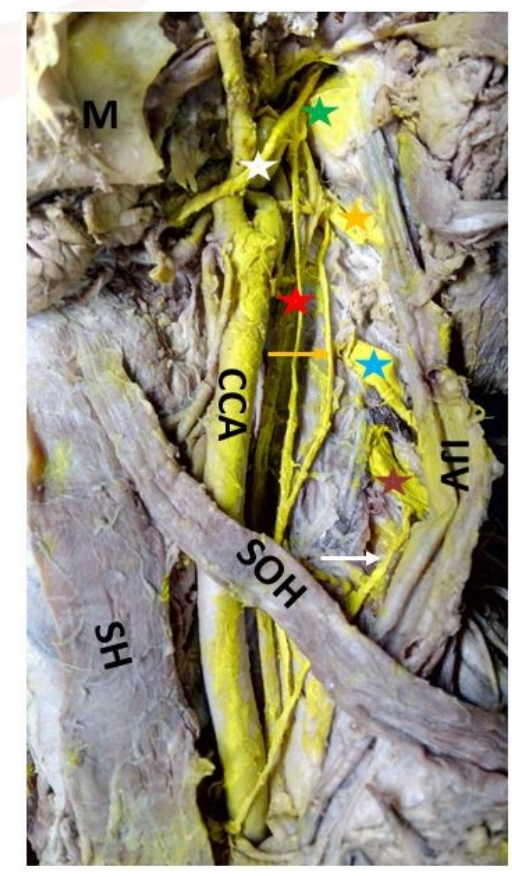

CCA - common carotid artery, IJV - Internal Jugular Vein, $\mathrm{M}$ - Mandible, SH - Sternohyoid, SOH - Superior belly of Omohyoid, White star - Hypoglossal Nerve, Red star - Descendant Hypoglossi, Green star - C1, Orange star - C2, Blue star - C3, Brown Star - C4, Orange Arrow (C2 fibers) - First Loop, White Arrow - Second Loop 
Fig. 3: Various types of ansa cervicalis and their formation.

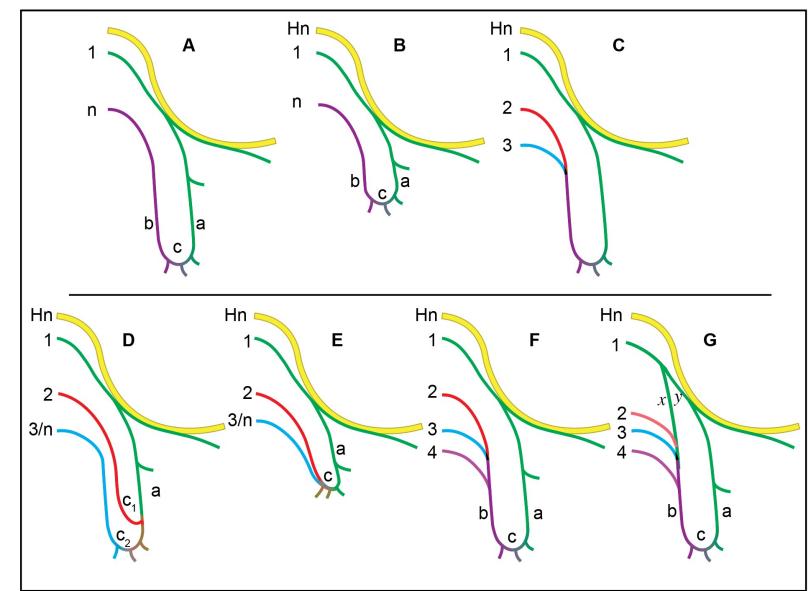

A-Single loop AC; B- short, single loop AC; C-typical AC; D- AC with two loops; E- Short AC with two loops; F- long $A C, C 2,3,4$ contribute to inferior root; $\mathbf{G}$ - inferior root contribution from $\mathrm{C} 1$ to $\mathrm{C} 4$.

1-C1; 2- C2; 3-C3; 4- C4; $\mathbf{n}$ - can be any cervical spinal nerve from $\mathrm{C} 1$ to $\mathrm{C} 4$; $\mathrm{Hn}$ hypoglossal nerve; a- superior root; b- inferior root; c- loop of ansa cervicalis; $\mathbf{c}_{\mathbf{1}}$ \& $\mathbf{c}_{\mathbf{2}}-$ superior and inferior loops respectively; $\mathbf{x} \& \mathbf{y}$ - C1 nerve bifurcating and contributing to superior and inferior root; AC- ansa cervicalis.

\section{DISCUSSION}

The current case variation of $A C$ on the right side of neck belongs to Type $D$ with contribution from $C 2,3$, but on left side by $C 3,4$ form inferior loop and join in form of long Ansa, inferior to superior belly of omohyoid (SBO). Hence, on the left side, AC can be said to be variant of Type $F$ (triple form; as per Caliot and Dumont classification) [4]. This type of variation is not described in literature.

The formation and in relations of ansa cervicalis in relation to the great vessels in the neck is complex. Various authors have tried to classify the variations.

Caliot and Dumont et al. (1986) in their detailed review on formation and type of $A C$, have enlisted different nomenclature and forms of AC. They defined the anastomoses and relations between hypoglossal nerve and cervical plexus following dissection in 80 cadavers. They termed $\mathrm{C} 1$ contribution to $\mathrm{AC}$ by joining hypoglossal nerve as superior anastomosis of Hypoglossal nerve and the Inferior anastomosis as that between C2,3 (and/or C4) and the hypoglossal nerve [4].

Superior root of AC: The SRAC has been described in the studies based on relation to posterior belly of digastric (PBDg). Most authors opined that it begins superior to PBDg, but as per Mwachaka PM et al (2010), its only in 56\%. Mwachaka PM noted absence of SRAC in one case, which could be due to hitch hiking of C1 along other nerves like Vagus nerve [1]. Chhetri \& Berke et al. (1997) noted that the SRAC courses lateral to ICA \& then ECA in most cases. It can sometimes relate medial to internal carotid artery (ICA) \& further below with common carotid artery (CCA) to join the inferior root [3]. In relation to the blood vessels, SRAC was superficial to ICA in $28 \%$ and superficial to external carotid artery (ECA) in 72\% [5].

In rare cases, SRAC can exit via the vagus nerve, which has been termed as aberrant ansa cervicalis $[6,7]$.

Inferior root of AC: Inferior root of ansa cervicalis (IRAC) was found to vary more compared to SRAC; since it was formed by more than one root. The contribution to IRAC has been described to be from $\mathrm{C} 2, \mathrm{C} 3, \mathrm{C} 4$ ventral rami in various combinations. Caliot \& Dumont have described the contribution to IR to be by $\mathrm{C} 3$ in $80 \%, C 2$ in $36 \%$ [4]. The contribution of different cervical spinal ventral rami observed among different studies is summarized in the Table 1.

Table 1: Contribution of cervical spinal roots to the Inferior Root of Ansa cervicalis.

\begin{tabular}{|c|c|c|}
\hline & Study sample & $\begin{array}{c}\text { Contribution by roots of } \\
\text { cervical spinal nerves to } \\
\text { the inferior root }\end{array}$ \\
\hline \multirow{6}{*}{ Caliot \& Dumont, 1986 [4] } & \multirow{6}{*}{80 cadavers } & $C 2,3-36 \%$ \\
\hline & & C3- $80 \%$ \\
\hline & & C2- $26 \%$ \\
\hline & & $\mathrm{C} 3,4-6 \%$ \\
\hline & & C4- $7.5 \%$ \\
\hline & & C1- $1 \%$ \\
\hline \multirow{5}{*}{ Poviraev NP et al. 1967 [8] } & \multirow{5}{*}{$\begin{array}{l}160 \text { still born } \\
\text { infant cadavers }\end{array}$} & $\mathrm{C} 2,3-74 \%$ \\
\hline & & $C 2,3,4-14 \%$ \\
\hline & & C3-5\% \\
\hline & & C2- $4 \%$ \\
\hline & & $\mathrm{C} 1,2,3-2 \%$ \\
\hline \multirow{4}{*}{ Loukas et al. 2007 [5] } & \multirow{4}{*}{100 cadavers } & $\mathrm{C} 2-12 \%$ \\
\hline & & C3- $40 \%$ \\
\hline & & $\mathrm{C} 2,3-38 \%$ \\
\hline & & $C 2,3,4-10 \%$ \\
\hline
\end{tabular}

As per Chettri and Berke, the cervical ventral rami unite before the summit of AC and form IRAC. The contributing branches travel independently and form the loop of AC, and they course on the surface of IJV [3]. 
The course and relation of IRAC has been described in relation to IJV. Two patterns have been described by Chettri et al.- IRAC can begin posterior to IJV, then cross lateral to it and become anterior where it anastomoses with SRAC. In the second pattern, the IRAC begins medial to IJV, courses between IJV and CCA. The most common point where SRAC and IRAC meet is over the lateral wall of IJV, medial to the

Table 2: Relationship of different parts of Ansa Cervicalis with adjacent structures.

\begin{tabular}{|c|c|c|c|c|c|c|c|c|}
\hline & $\begin{array}{l}\text { Relationship with the } \\
\text { anatomical structure }\end{array}$ & \begin{tabular}{|c|}
$\begin{array}{c}\text { Caliot et al } \\
(1986)\end{array}$ \\
\end{tabular} & \begin{tabular}{|c|}
$\begin{array}{c}\text { Loukas et al } \\
(2007)\end{array}$ \\
\end{tabular} & \begin{tabular}{|c|}
$\begin{array}{c}\text { Mwachaka PM } \\
\text { et al (2010) }\end{array}$ \\
\end{tabular} & Grant et al & \begin{tabular}{|c|} 
Anatoly et al. \\
(2018) \\
\end{tabular} & $\begin{array}{c}\text { Banneheka } \\
\text { (2008) }\end{array}$ & Comments \\
\hline \multirow{3}{*}{ SRAC* } & Above digastric & 75 & 92 & 56 & NA & NA & NA & \multirow{3}{*}{$\begin{array}{l}\text { A) Absent SRAC in one case- could have } \\
\text { hitch-hiked other nerves viz. vagus } \\
\text { nerve. (Mwachaka) } \\
\text { B) Average two branches- supply SBO } \\
\text { (rare- sternohyoid, sternothyroid or } \\
\text { sternocleidomastoid) (“) }\end{array}$} \\
\hline & At the level & 25 & NA & 4 & NA & NA & NA & \\
\hline & Below digastric & NA & NA & 38.7 & NA & NA & NA & \\
\hline \multirow{2}{*}{ IRACף } & Lateral to IJV & 81 & 74 & 81.5 & 57 & 66 (external) & 33.7 & \multirow{2}{*}{$\begin{array}{l}\text { IRAC absent in about } 3 \% \text {. Nerve roots } \\
\text { contributing to IRAC, could have hitch- } \\
\text { hiked on the XII cranial nerve. }\end{array}$} \\
\hline & Medial to IJV & 15 & 26 & 19.5 & 43 & 34 (internal) & 63 & \\
\hline \multirow{3}{*}{$\begin{array}{l}\text { Loop/ Summit of } \\
\text { AC }\end{array}$} & At the level of SBO§ & 64 & & 10.8 & NA & NA & NA & \multirow{3}{*}{$\begin{array}{l}\text { The branches from the loop supply the } \\
\text { infrahyoid muscles }\end{array}$} \\
\hline & Above SBO§ & 21 & 30 & 64.6 & NA & NA & NA & \\
\hline & Below SBO§ & 15 & 70 & 24.6 & NA & NA & NA & \\
\hline
\end{tabular}

Note: *-SRAC- superior root of Ansa cervicalis; १-IRAC-inferior root of Ansa cervicalis; §-SBO- superior belly of omohyoid; NA- not available; AC- ansa cervicalis.

IRAC was noted absent by Mwachaka et al in $10.5 \%$ on right side and $18.4 \%$ on left side. It was proposed that roots contributing to IRAC could have hitch-hiked along hypoglossal nerve, leading to its absence [1]. Caliot et al mention anastomoses by other nerves like- IRAC with cervical sympathetic (5 out of 80 ), cervical sympathetic with hypoglossal (2/80) and hypoglossal with phrenic in 2 out of 80 cases (has been called as anastomosis of Valentin [4].

Anatoly et al. (2018), did study on 56 cadavers. They classify the inferior root as external, if IRAC is lateral to IJV; and internal if IRAC is medial to IJV.

Summit of AC: The location of the summit of $A C$ has been discussed in relation to the inferior border superior belly of omohyoid (SBO) muscle. The commonest position of the loop was at the point where SBO crosses the great vessels in $64 \%$. The length of the loop depends on the length of IRAC, hence location of loop varies. The loop was said to be short if it was superior to the muscle (19\%) and if loop was inferior to the muscle, Long Ansa loop (15\%) [4]. Whereas Loukas et al, found Long AC in $70 \%$ and short $A C$ in $30 \%$.

Caliot et al noted absence of AC in 2 out of 80 cases (2.5\%) [5].

Anatoly et al point to the fact that, if the number of two roots form IRAC, length of AC is short. As the number of roots increase, or if the roots join independently, AC tends to be longer [10].

As per Chhetri and Berke, AC is said to be asymmetric. Studies indicate that SRAC is symmetric, but IRAC was symmetric in $25 \%$ cases. The location and length of $A C$ is said to depend on the roots forming the IRAC and the site where it anastomoses with SRAC [3].

Anatoly et al. have mentioned the use of superior border of thyroid cartilage (SBT) to describe the topography of AC. They measured distance between superior border of thyroid cartilage and the summit of loop and three groups were noted-i) Group A- $15 \mathrm{~mm}$ from SBT cartilage ii) Group B- $16-30 \mathrm{~mm}$ from SBT cartilage iii) Group C- more than $30 \mathrm{~mm}$ below the SBT cartilage [10].

When the classifications of different appearances of AC (as per Caliot and Dumont and Loukas et al) was compared ( 7 forms of $A C$ ), the nomenclature adapted differs. Loukas classification has been termed in Roman numeralsType I, II and so on, whereas former has termed in alphabets- Type A, B and so on. The double classic type has been termed as Type I by Loukas. The description of each type is also different in 
these two, and given in the comparison Table 3. In Fig 3, the various types of ansa cervicalis has been depicted which shows that this nerve plexus varies in formation, from being a single loop to multiple loops depending on the roots contributing. It can be short ansa or long AC, and the roots of IRAC can join at an acute angle with SRAC.

The different forms classified by Caliot and Dumont, doesn't explain how different roots contribute to the variation in the forms of $A C$. If quadruple form is considered, which roots of cervical plexus form the IRAC is not explained [4].

In study by Banneheka S, study was done on 106 cadavers. They classify the ansa cervicalis into seven groups based on formation of inferior root from $\mathrm{C} 1,2,3,4$ in various combinations and morphology [9].
But Anatoly et al, discuss the classification systems of ansa cervicalis based on six parameters [10]:

1) Number of loops: it can be one, two or three loops.

2) Relation to IJV- lateral (external) or medial (internal) to the vein.

3) Based on the location in relation to superior border of thyroid cartilage: a) high location- < $15 \mathrm{~mm}$ below SBT; b) middle location- $16-30 \mathrm{~mm}$ below SBT; c) low location- > $30 \mathrm{~mm}$ below SBT. 4)Contribution to superior root-a) C1; b) C1, C2. 5) Contribution to inferior root-a) C2; b) C2, C3. Origin of SRAC: a) hypoglossal nerve;

b) vagus nerve.

Table 3: Comparison of classification of forms of Ansa cervicalis by Caliot et al and Loukas et al (Refer Fig 1).

\begin{tabular}{|l|c|c|c|c|}
\hline \multicolumn{1}{|c|}{ Description of Ansa cervicalis } & $\begin{array}{c}\text { Caliot \& } \\
\text { Dumont } \\
\text { (1986) }\end{array}$ & $\begin{array}{c}\text { Percentages In } \\
\text { brackets- number of } \\
\text { cases/80 specimens }\end{array}$ & Loukas et al (2007) & Percentages \\
\hline Simple classic & $\mathrm{A}$ & $27 \%(22 / 80)$ & Type II & $20 \%$ \\
\hline Very short, single & $\mathrm{B}$ & $1.25 \%(1 / 80)$ & Type VII & $3 \%$ \\
\hline Double classic & $\mathrm{C}$ & $40 \%(32 / 80)$ & Type I & $35 \%$ \\
\hline Double form with two separate loops & $\mathrm{D}$ & $11 \%(9 / 80)$ & Type III & $20 \%$ \\
\hline Double short form & $\mathrm{E}$ & $7.5 \%(6 / 80)$ & Type V & $8 \%$ \\
\hline Triple form & $\mathrm{F}$ & $8 \%(7 / 80)$ & Type IV & $10 \%$ \\
\hline Quadruple type & $\mathrm{G}$ & $1.25 \%(1 / 80)$ & Type VI & $4 \%$ \\
\hline
\end{tabular}

Jelev L (2013) classified the ansa cervicalis into five types based on contribution by cranial and cervical spinal segments. Type I- absent ansa; Type II- typical AC; Type III- hypogloss-vagocervical ansa; Type IV- vago-cervical ansa; Type $\mathrm{V}$ - absent ansa, C1 traverses via hypoglossal nerve and $\mathrm{C2}, \mathrm{C3}, \mathrm{C4}$ via vagus nerve [6].

So, we observe that the path taken by $\mathrm{C} 1$ to $\mathrm{C} 4$ spinal nerves to innervate the infrahyoid muscles vary, and if ansa is not formed, the muscles are supplied directly [6]. These variations are important for surgeons who operate in this area.

\section{CONCLUSION}

We hereby report variants in the ansa cervicalis, which can add to the existing literature as discussed. During literature search, we came across authors who have classified the ansa cervicalis by various parameters. They have used digastric muscle for the superior root of ansa cervicalis. In case of inferior root, internal jugular vein has been taken as landmark. And for the loop, superior belly of omohyoid muscle is considered. Recently, authors have utilized upper border of thyroid cartilage in measuring the length of ansa cervicalis. The morphology and topographical relations are relevant in reinnervation procedures of larynx, head and neck surgeries in this area of neck.

\section{Conflicts of Interests: None}

\section{REFERENCES}

[1]. Mwachaka PM, Ranketi SS, Elbusaidy H, Ogeng'o J. Variations in the anatomy of ansa cervicalis. Folia Morphol 2010; 69:160-3. 
[2]. Kumar N, Patil J, Mohandas RKG, Nayak SB, Guru A. Rare case of double looped ansa cervicalis associated with its deep position in the carotid triangle of the neck. Ann med health sci res 2014; 4(Suppl 1): 29-31.

[3]. Chhetri DK, Berke GS. Ansa cervicalis nerve: Review of the topographic anatomy and morphology. Laryngoscope 1997; 107:1366-72.

[4]. Caliot P, Dumont V, Bousquet V, Midy D. A note on the anastomoses between the hypoglossal nerve and cervical plexus. Surg Radiol Anat 1986; 8:7579.

[5]. Loukas M, Thorsell A, Tubbs RS, Kapos T, Louis RG, Jr, Vulis $M$, et al. The ansa cervicalis revisited. Folia Morphol. 2007; 66:120-5.

[6]. Jelev L. Some unusual types of formation of the ansa cervicalis in humans and proposal of a new morphological classification. Clin Anat. 2013; 26(8);961-5.
[7]. Manjunath KY. Vagal origin of the ansa cervicalis nerve: report of two cases. Indian J Otolaryngol Head Neck Surg 2000; 52:257-8.

[8]. Poviraev NP, Chernikov YF. Anatomy of the ansa cervicalis. Except.Med. 1967;21:219.

[9]. Banneheka S. Morphological study of the ansa cervicalis and the phrenic nerve. Anat Sci Int. 2008; 83: 31-44.

[10]. Anatoly IS, Oganesyan MV, Hammer CM, Paulsen F, Bakhmet AA. Ansa cervicalis-a new classification approach. Ann Anat. 2018; 222: 55-60. https:// doi.org/10.1016/j.aanat.2018.10.010.

How to cite this article:

Suma H Y, Yogesh A S, Shanthini S. A RARE CASE OF BILATERAL VARIANT ANSA CERVICALIS AND REVIEW OF LITERATURE. Int J Anat Res 2019;7(2.2):6565-6570. DOI: 10.16965/ijar.2019.168 